\title{
TREND ANALYSIS OF TUBERCULOSIS CASES AND THE EFFECT OF HIV CASES ON TUBERCULOSIS CASES IN SOME WEST AFRICAN COUNTRIES USING PANEL POISSON AND NEGATIVE BINOMIAL REGRESSION MODELS
}

\section{Monday Osagie ${ }^{1,2}$ Adenomon \& Gbenga Solomon ${ }^{1}$ Akinyemi}

\author{
1. Department of Statistics \& NSUK-LISA Stat Lab \\ Nasarawa State University, Keffi, Nigeria \\ 2. Foundation of Laboratory for Econometrics and Applied Statistics of Nigeria (aka \\ FOUND-LEAS-IN-NIGERIA) \\ adenomonmo@nsuk.edu.ng; gbengaakinyemi76@gmail.com
}

Tel: $+2347036990145 ;+2348067652424$

2. https://orcid.org/0000-0002-9523-8032

\begin{abstract}
Tuberculosis is a leading cause of death worldwide and the leading cause from a single infectious agent, ranking above Human immunodeficiency virus (HIV) and Acquired Immune Deficiency Syndrome (AIDS). The aim of this study is to ascertain the trend of tuberculosis prevalence and the effect of HIV prevalence on Tuberculosis case in some West African countries from 2000 to 2016 using count panel data regression models. The data used annual HIV and Tuberculosis cases spanning from 2000 to 2016 extracted from online publication of World health Organization (WHO). Panel Poisson regression model and Negative binomial regression model for fixed and random effects were used to analyzed the count data, the result revealed a positive trend in TB cases while increased in HIV cases leads to increase in TB cases in West African countries. Among the competing models used in this study, Panel Negative Binomial Regression Model with fixed effect emerged the best model with log likelihood value of -1336.554. This study recommended that Government and NGOs need more strategies to fight against HIV menace in West Africa as this will in turn reduced TB cases in West Africa.
\end{abstract}

Keywords: Tuberculosis (TB), Human immunodeficiency virus (HIV), Acquired Immune

Deficiency Syndrome (AIDS), World health Organization (WHO), Panel Data, Poisson, Negative Binomial, Regression

\section{Introduction}

Tuberculosis is sometime referred to as 'the silent killer'. This disease is considered the $9^{\text {th }}$ leading cause of death in 2016, and found to rate higher than HIV in term of infection and transmission (WHO, 2017). Seven countries amounted for 64\% of TB infection globally which 
include Nigeria and other Countries such as, India, Indonesia, China, Philippines Pakistan and South Africa. In the order of most infected countries by TB, Nigeria ranked $6^{\text {th }}$ (Ogbo et al. , 2018).

Due to the havoc of TB and HIV diseases in Africa and the world at large, one may ask the following questions:

i. What is the trend of tuberculosis prevalence among West African countries?

ii. Is there any significant relationship between patients having tuberculosis as a result of being infected with HIV/AIDS among the West African?

The aim of this study is to examine the trend of tuberculosis prevalence and the dynamic interrelationship between TB and HIV prevalence among some West African countries using count panel data regression models.

\section{LITERATURE REVIEW}

Brosch, et al., (2002), suggested that TB bacteria (Mycobacterium tuberculosis) is curable and preventable, it now depend on how much we deepen how fight against it further spread in any community while WHO (2017) Global Tuberculosis Report highlighted that TB can be spread from person to person through the air. In a review on the assessment of the trend in TB in Africa Chatterjee \& Pramanikit (2015) discovered that unprecedented growth of the tuberculosis epidemic in Africa is attributable to several factors, the most important being the HIV epidemic. Tuberculosis is commonly associated with death from HIV/AIDS autopsy studies have shown that 30 to $40 \%$ of HIV-infected adults die from TB. Among HIV-infected children, TB accounts for up to one in five of all deaths. $70 \%$ of adults and $88 \%$ of children infected with HIV 
worldwide live in sub-Saharan Africa. In addition, malnutrition is one of the factors that can promote TB infection. (Cegielski and McMurray, 2004)

Umeh et al., (2007) carried out an investigated among patients referred to a chest clinic in Nasarawa State by examining 344 patients who presented with respiratory problems at the clinic, it was discovered that $44.8 \%$ had M. tuberculosis infection, $24.7 \%$ HIV infection and $12.8 \%$ HIV/tubercle bacilli co-infection. It was also found that Co-infection rate in HIV infected persons (HIV+) was 51.8 and $28.6 \%$ in those with M. tuberculosis infection. The relative risk of HIV positive persons being co-infected was 1.075, while it was 0.401 for TB infected persons. The estimated Odds Ratio (OR) shows that the risk of co-infection was 2.68 times higher among HIV+ persons than among those with tuberculosis. The attributable risk of $45 \%$ was found and shows the extent to which co-infection could be attributed to HIV infection. A key socioeconomic variable, eating in groups, was significantly correlated with co-infection $(r=0.107$; $\mathrm{p}<$ 0.05). it was finally concluded that his result corroborates the finding (Brown et al., 2006) that tuberculosis is highest among people infected with HIV and that HIV infection is likely to be one of the factors responsible for the recent increase in tuberculosis.

Askar (2008) examined Tuberculosis and HIV co-infection in two district in Somaliland using 839 patient. The study employed logistic regression model and the result revealed HIV seroprevalence among TB patient in Somaliland had increased Over time.

Njepuome and Odume (2009) examined the impact of HIV syndromes in the treatment of TB cases in Gombe state Nigeria using 300 patents with HIV and TB. The study revealed no significant difference in the mean age of male and female. The study also revealed that the death rate among dually infected patient was higher compare to patient with only HIV negative status. 
Pimpin and Drumright (2011) carried out a systematic review to determine the burden of TBHIV infection in the European Union and European Economic Area on 10 academic literature databases which were searched between September and October 2009:. The review carried out on information collected in 1996 and later, regardless of the year of initiation of data collection and narrative synthesis presented reveals that the proportion of HIV-co-infected patient varied from 0 to $15 \%$. Higher level and increasing trend of infection was recorded in the Western and Eastern countries compared with the central European Union / European Economic Area.

Cajetan et al., (2017) examined the Prevalence of drug-resistant tuberculosis in Nigeria using a systematic review and meta-analysis identified that 34 anti-TB drug resistance surveys with 8002 adult TB patients consisting of 2982 new and 5020 previously-treated cases. The prevalence rate of any drug resistance among new TB cases was 32.0\% (95\% CI 24.0-40.0\%; 734/2892) and among previously treated cases, the rate was 53.0\% (95\% CI 35.0-71.0\%; 1467/5020). Furthermore, multidrug resistance among new and previously-treated cases was $6.0 \%$ (95\% CI $4.0-8.0 \% ; 161 / 2502)$ and $32.0 \%(95 \%$ CI 20.0-44.0; 357/949), respectively. Heterogeneity was significant in the studies. It was concluded that the burden of drug resistance TB in Nigeria is high and as such immediate survey needs to be carried out and measure taken to curb the increasing trend.

Akinleye et al. (2015) carried out a prospective study on Tuberculosis and HIV co-infection among patients attending directly observed treatment short course (DOTS) in Lagos, Nigeria case study of Ojo local government area. This study was carried out to determine the prevalence of HIV/TB co-infection among tuberculosis patients in DOTS Centre in Lagos. This study was carried out between January 2013 and August, 2014 in Ojo Local Government (DOTS) Centre, 
in Lagos, Nigeria. Five hundred and nine (509) DOTS attendees (270 females and 239 males, age-range 10-70years of age, at the Ojo and Okoko health services Centre. Samples of sputum and blood were collected and processed using standard laboratory procedures. All the patients' sera were screened for antibodies for HIV1\& 2 using three rapid ELISA kits. The study showed that there is no significant relationship with a total of one hundred and twenty eight $(25.1 \%)$ of HIV infection among diagnosed TB patients. HIV/TB co-infection positive patients for male and female were $25.6 \%$ and $24.8 \%$ respectively. Finally it was concluded that The results of the work show a high burden of HIV/TB co-infection in Lagos state, southwestern Nigeria the overall prevalence of HIV infection among diagnosed TB patients was 128(25.1\%) is higher than previously reported among this category of patients in the state.

Andrzej et al., (2012) Having examined Tuberculosis and HIV Co-Infection found that the incidence and mortality rates for new AIDS-defining opportunistic infections have been shown to be higher if individuals with HIV are co-infected with TB, they also noted that TB/HIV coinfection represents a novel pathogenic scenario at the global level. It constitutes a serious diagnostic and therapeutic challenge and, particularly in poor countries, weighs heavily on already strained health care budgets. It has recently been realized that the epidemiology, clinical manifestations, and management of both HIV and M. tuberculosis infections are different and far more complex in co-infected compared to mono-infected patients. However, our knowledge about the mechanisms of interaction of the two pathogens still has many gaps that need to be filled in order to develop preventive measures against the two diseases.

Pontali et al., (2011) under gone a study on Tuberculosis and HIV co-infection bearing in mind question like do we have a surveillance system in Europe? Is there any reason why a clinician 
should be interested in knowing about the state of the art in tuberculosis (TB) and HIV coinfection surveillance in Europe? Came up with answers like is probably easier to answer, at least at a global level: TB-HIV co-infection is responsible for almost 400,000 deaths every year and TB is by far the major killer of HIV-infected persons, being responsible for over a quarter of the global burden of HIV-associated deaths; people living with HIV/AIDS infected with Mycobacterium tuberculosis are at 20-30 times greater risk of developing TB compared with HIV-uninfected persons.

Aweke et al. (2016) Examining Prevalence and associated factors of TB/HIV co-infection among HIV Infected patients in Amhara region, Ethiopia. There were 571 respondents in the study. Of these, 413 (72.3\%) were not found to have TB/HIV-co infection while 158(27.7\%) had TB/HIV co-infection. The proportion of female respondents who had TB/HIV-co infection accounted for a larger proportion in the sample $107(69 \%)$ compared to male respondents $48(31 \%)$. Patients with primary education accounted for the larger proportion $64(40 \%)$ of having TB/HIV coinfection compared to those with no education 39(24.8\%), secondary education 33(21\%), and certificate and above $21(13.4 \%)$. In addition, majority of TB/HIV patients $130(82.8 \%)$ were urban residents while 27(17.2\%) were residing in rural areas. Among TB/HIV co-infected patients, 149(96.8\%) were non-smokers $123(79.9 \%)$ of TB/HIV co-infected patients were nonalcoholics. The majority of participants who had TB/HIV co-infection, 104(67.5\%) were in WHO clinical stage of III followed by WHO clinical stage IV 23(14.9\%) and WHO clinical stage II $19(12.3 \%)$. Only $8(5.2 \%)$ study participants who have TB/HIV-co infection were found to be in WHO clinical stage I. Chi-square test shows that the TB/HIV co infection is significantly associated with marital status, alcohol intake, baseline CD4 count, baseline WHO clinical stage, baseline functional status, TB Smear type (p-value $<0.05)$. 


\section{RESEARCH METHODOLOGY}

This section looks at the methodology used to achieve the objectives of the study. Also discussed in this section are the research design, data types and sources, and the model specification important to the objectives of the study. The estimation techniques used to ascertain the likely causal relationship was addressed also.

The population target for the study is West African countries which comprises of 16 countries, but for the purpose of this research only 10 West African countries will be covered. i.e Benin, Burkina Faso, Gambia, Ghana, Guinea Bissau, Liberia, Mali, Niger, Nigeria and Serra Loane, for a period of 17 years (2000 to 2016). The data was sourced from the WHO (2018) Publications.

\section{Model Specification}

Panel data are also called longitudinal data or cross-sectional time-series data. These longitudinal data have observations on the same units in several different time periods (Kennedy, 2008). A panel data set has multiple entities, each of which has repeated measurements at different time periods. Panel data may have individual (group) effect, time effect, or both, which are analyzed by fixed effect and/or random effect models. longitudinal data have more variability and allow to explore more issues than do cross-sectional or time-series data alone (Kennedy, 2008).

Baltagi (2001) revealed that Panel data give more informative data, more variability, less collinearity among the variables, more degrees of freedom and more efficiency. Green (1997) further explained that if individual effects are significant then this is a sign that a significant component of the model is accounted for by the individual effect parameter and so fixed effect might be preferred over the random effect. However Log likelihood test statistic was used to 
determine which is best between the fixed and random effect model. The layout of panel data is given below:

\begin{tabular}{|c|c|c|c|}
\hline & & $\operatorname{trry}_{1}, Y e$ & tetry, \\
\hline $\mathrm{try}_{1}, \mathrm{Year}_{2}$ & $\begin{array}{c}X_{1} \text { country }_{1}, \text { Year }_{2} \\
:\end{array}$ & $\begin{array}{c}X_{2} \text { country }_{1}, \text { Year }_{1} \\
:\end{array}$ & $X_{k}$ country $_{1}$, Year $_{2}$ \\
\hline Ycountry $_{1}$, Year $_{T}$ & $X_{1}$ country $_{1}$, Year $_{T}$ & $X_{2}$ country $_{1}$, Year $_{T}$ & $X_{k}$ country $_{1}$ Year $_{T}$ \\
\hline Ycountry $_{2}, Y_{e a r_{1}}$ & $X_{1}$ country $_{L_{2}}$ Year $_{1}$ & $X_{2}$ country $_{L_{t}}$, Year $_{1}$ & $X_{k}$ country $_{2,}$ Year $_{1}$ \\
\hline $\begin{array}{c}\text { Ycountry }_{2}, \\
\vdots\end{array}$ & $X_{1}$ country $_{2}$, Year $_{2}$ & $X_{2}$ country $_{2}$, Year $_{2}$ & $X_{k}$ country $y_{2}$, Year $_{2}$ \\
\hline Ycountry $_{2}$, Year $_{T}$ & $X_{1}$ country $_{2}$, Year $_{T}$ & $X_{2}$ conntry $_{2}$, Year $_{T}$ & $X_{k}$ country $_{2}$ Year \\
\hline Ycountry $_{3}$, Year $_{1}$ & trtry $y_{3}$ Year $_{1}$ & utry, $y_{3}, Y_{e a r_{1}}$ & $X_{k}$ country $_{1}, Y_{e a r_{1}}$ \\
\hline $\begin{array}{c}\text { Vonentry } y_{3}, \text { Vem } \\
\vdots\end{array}$ & $\begin{array}{c}X_{1} \text { conntry }_{3}, \text { Yenr } \\
\vdots\end{array}$ & $\begin{array}{c}X_{2} \text { contryty }_{3}, \text { Yenr } \\
\vdots\end{array}$ & $\begin{array}{c}X_{k} \text { country } y_{3} \text { Year } \\
\vdots\end{array}$ \\
\hline Ycountry, $_{3}$, Year & $X_{1}$ country $_{3}$, Year $_{T}$ & $X_{2}$ country $_{3}, Y_{\text {ear }}$ & $X_{k}$ country $_{3} Y_{e a r_{T}}$ \\
\hline Ycountry $_{n,}$, Year & $X_{1} c$ & $\mathrm{X}_{2} \mathrm{Co}$ & $y_{N}, Y_{e a r_{1}}$ \\
\hline $\begin{array}{c}\text { Ycountry } y_{n} \\
\vdots\end{array}$ & $\begin{array}{c}X_{1} \text { country }_{N}, \\
:\end{array}$ & $\begin{array}{c}X_{2} \text { country }_{N}, Y^{\prime} \operatorname{Year}_{1} \\
:\end{array}$ & $\begin{array}{c}X_{k} \text { country }_{N}, Y^{\prime}{ }^{\prime} r_{2} \\
\vdots\end{array}$ \\
\hline 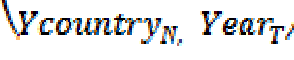 & $X_{1}$ country $_{N}, Y$ & $X_{2}$ country $_{N}, Y$ & $X_{k}$ country $_{N}$ \\
\hline
\end{tabular}

The generalized linear model for panel data is specified as:

$$
\mathrm{y}_{\mathrm{it}}=\alpha+\beta \mathrm{x}_{\mathrm{it}}+\varepsilon_{\mathrm{it}}
$$

Where

i: stands for the cross sectional variable

$$
\mathrm{i}=1, \ldots . \mathrm{N}
$$

$\mathrm{t}$ : stands for the time series

$$
\mathrm{t}=1, \ldots . \mathrm{T}
$$

$\mathrm{y}_{\mathrm{it}}$ : stands for the dependent variable (it will be denoted as number of cases resulting from Tuberculosis) 
$\mathrm{X}_{\mathrm{it}}$ : stands for the independent variable (it will denote explanatory variable which will include time period and cases of HIV)

$\alpha$ : stands for the intercept

$\beta$ : stands for the coefficient of the independent variable

$\varepsilon_{\mathrm{it}}:$ stands for the error term

The Basic Linear Panel Models are

Pooled model (or population average)

$$
\mathrm{y}_{\mathrm{it}}=\alpha+\beta \mathrm{x}_{\mathrm{it}}^{\prime}+\mathrm{u}_{\mathrm{it}}
$$

Two-way effects model allows intercept to vary over i and $\mathrm{t}$

$$
\mathrm{y}_{\mathrm{it}}=\alpha+\gamma_{\mathrm{t}}+\beta \mathrm{x}^{\prime}{ }_{\mathrm{it}}+\varepsilon_{\mathrm{it}}
$$

Individual-specific effects model

$$
y_{i t}=\alpha_{i}+\beta x^{\prime}{ }_{i t}+\varepsilon_{i t}
$$

Where $\alpha$ i may be fixed or random effect.

Mixed model or random coefficients model allows slopes to vary over

The fixed effect (FE) model takes $\alpha_{i}$ to be a group of specific constant term in the regression equation.

Individual-specific effects model:

$$
\mathrm{y}_{\mathrm{it}}=\alpha_{\mathrm{i}}+\beta_{1} \mathrm{X}_{1 \mathrm{it}}+\beta_{2} \mathrm{X}_{2 \mathrm{it}}+\ldots .+\beta_{\mathrm{k}} \mathrm{X}_{\mathrm{kit}}+\varepsilon_{\mathrm{it}}
$$

$\checkmark \quad \alpha_{\mathrm{i}}$ is a random variable possibly correlated with $\mathrm{x}_{\text {it }}$

$\checkmark$ So regressor $\mathrm{x}_{\text {it }}$ may be endogenous (wrt to $\alpha_{\mathrm{i}}$ but not $\varepsilon_{\mathrm{it}}$ )

$\checkmark$ Pooled OLS, pooled GLS and RE are inconsistence for $\beta$ 
Within (FE) and first difference estimators are consistent.

or in the matrix notation

$$
y_{i t}=\alpha_{i}+\beta x^{\prime}{ }_{i t}+\varepsilon_{i t}
$$

where

$$
\mathrm{X}^{\prime}{ }_{\mathrm{it}}=\left[\mathrm{X}_{1 \mathrm{it}}, \mathrm{X}_{2 \mathrm{it}}, \ldots . ., \mathrm{X}_{\mathrm{kit}}\right]
$$

and

$$
\beta^{\prime}=\left[\beta_{1}, \beta_{2}, \beta_{3} \ldots . ., \beta_{\mathrm{k}}\right] .
$$

The " $i$ " indexes cross-section realizations so that $\mathrm{i}=1,2,3, \ldots . \mathrm{N}$ (countries) and "t" indexes timeseries realizations so that $\mathrm{t}=1,2,3 \ldots \ldots \mathrm{T}$ (Time). While the individual effect $\alpha_{\mathrm{i}}$ is regarded as the constant over time (t) and specific to the individual cross-sectional unit (i) denoted here as West African countries. The $\alpha_{\mathrm{i}}$ is expected to capture the unobservable, and non-measurable characteristics that differentiate individual units.

Fundamental assumption of the fixed effect model

$\mathrm{E}\left[\varepsilon_{\mathrm{it}}\right]=0$

$\operatorname{Cov}\left(\varepsilon_{\mathrm{it}}, \varepsilon_{\mathrm{jt}}\right)=0$,

$\operatorname{Var}\left(\varepsilon_{\mathrm{it}}\right)=\mathrm{E}\left[\varepsilon^{2}{ }_{\mathrm{it}}\right]=\sigma_{\mathrm{e}}^{2}$

$\mathrm{E}\left[\varepsilon_{\mathrm{it}}, \mathrm{X}_{1 \mathrm{it}}\right]=\mathrm{E}\left[\varepsilon_{\mathrm{it}}, \mathrm{X}_{2 \mathrm{it}}\right]=\mathrm{E}\left[\varepsilon_{\mathrm{it}}, \mathrm{X}_{3 \mathrm{it}}\right]=\mathrm{E}\left[\varepsilon_{\mathrm{it}}, \mathrm{X}_{4 \mathrm{it}}\right]=\ldots \ldots . .=\mathrm{E}\left[\varepsilon_{\mathrm{it}}, \mathrm{X}_{\mathrm{kit}}\right]=0$ and the $\mathrm{X}_{\mathrm{kit}}$ is not invariant. It should be noted that under this assumptions, the OLS can be used to obtain the unbiased, consistent and efficient BLUE parameter estimate 
Random effect (RE) or population-average (PA): this is also known as the error component model, includes a non-measurable stochastic variable, which differentiates individuals. It is written thus:

$$
y_{i t}=\alpha_{i}+\beta_{1} X_{1 i t}+\beta_{2} X_{2 i t}+\ldots .+\beta_{k} X_{k i t}+u_{i}+\varepsilon_{i t}
$$

$\checkmark \quad \alpha_{\mathrm{i}}$ is a random variable possibly correlated with $\mathrm{x}_{\mathrm{it}}$

$\checkmark$ So regressor $\mathrm{x}_{\text {it }}$ may be exogenous (wrt to $\alpha_{\mathrm{i}}$ but not $\varepsilon_{\mathrm{it}}$ )

$\checkmark$ Pooled OLS, pooled GLS and RE are inconsistence for $\beta$

$\checkmark$ Ui is a stochastic variable

or in the matrix notation

$$
y_{i t}=\alpha_{i}+\beta x^{\prime}{ }_{i t}+u_{i}+\varepsilon_{i t}
$$

where

$$
\mathrm{X}^{\prime}{ }_{\mathrm{it}}=\left[\mathrm{X}_{1 \mathrm{it}}, \mathrm{X}_{2 \mathrm{it}}, \ldots ., \mathrm{X}_{\mathrm{kit}}\right]
$$

and

$$
\beta^{\prime}=\left[\beta_{1}, \beta_{2}, \beta_{3} \ldots \ldots, \beta_{\mathrm{k}}\right]
$$

The "i" indexes cross-section realizations so that $\mathrm{i}=1,2,3, \ldots . . \mathrm{N}$ (countries) and "t" indexes timeseries realizations so that $t=1,2,3 \ldots \ldots \mathrm{T}$ (Time). The term $\mathrm{u}_{\mathrm{i}}$ is stochastic variable that embodies the unobservable or non-measurable distance that later account for individual distance. Essentially, the effect is thought to be a random individual effect rather than a fixed parameter.

Fundamental assumption of the random effect model

$$
\begin{aligned}
& \mathrm{E}\left[\mathrm{u}_{\mathrm{i}}, \mathrm{X}_{1 \mathrm{it}}\right]=\mathrm{E}\left[\mathrm{u}_{\mathrm{i}}, \mathrm{X}_{2 \mathrm{it}}\right]=\mathrm{E}\left[\mathrm{u}_{\mathrm{i}}, \mathrm{X}_{3 \mathrm{it}}\right]=\mathrm{E}\left[\mathrm{u}_{\mathrm{i}}, \mathrm{X}_{4 \mathrm{it}}\right]=\ldots \ldots . .=\mathrm{E}\left[\mathrm{u}_{\mathrm{i}}, \mathrm{X}_{\mathrm{kit}}\right]=0 \\
& \mathrm{E}\left[\varepsilon_{\mathrm{it}}\right]=\mathrm{E}\left[\mathrm{u}_{\mathrm{i}}\right]=0
\end{aligned}
$$


$\operatorname{Cov}\left(\mathrm{u}_{\mathrm{i}}, \varepsilon_{\mathrm{jt}}\right)=\mathrm{E}\left[\mathrm{u}_{\mathrm{i}}, \varepsilon_{\mathrm{it}}\right]=\sigma_{\varepsilon, \mathrm{u}^{2}}$

$\operatorname{Var}\left(\mathrm{u}_{\mathrm{i}}\right)=\mathrm{E}\left[\mathrm{u}_{\mathrm{i}}^{2}\right]=\sigma_{\mathrm{u}}^{2}$

Assuming normality $\mathrm{u}_{\mathrm{i}} \sim \mathrm{N}\left(0, \sigma_{\mathrm{u}}^{2}\right), \varepsilon_{\mathrm{it}} \sim \mathrm{N}\left(0, \sigma_{\mathrm{e}}^{2}\right)$, where both " $\mathrm{u}_{\mathrm{i}}$ " and " $\varepsilon_{\mathrm{it}}$ " are stochastic variables but form a composite error term called omega $\left(u_{i}+\varepsilon_{i t}\right) \equiv \omega_{i t}$

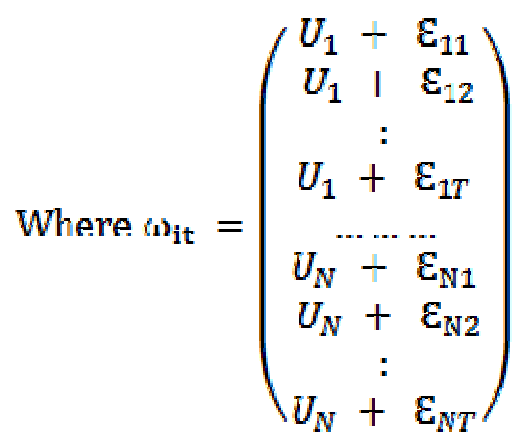

Since the research data are count in nature the panel count data model will be specifically used to model the data thus:

(a). Poisson Regression Model: the Poisson regression model is used for modeling count data and is usually the limiting form of binomial distribution. It is the probability of a random event $\mathrm{X}$ occurring in an interval of time. It is denoted by, $\operatorname{Pr}(X=x)=\frac{e^{-\lambda} \lambda \mathrm{x}}{x !} ; \mathrm{x}=0,1,2,3 \ldots \ldots . \mathrm{N}$. with mean and variance as $\lambda$ and the skewness and kurtosis of the distribution been $\frac{1}{\sqrt{\lambda}}$ and $3+\frac{1}{\lambda}$ respectively.

(b). Negative Binomial Regression Model. This is the probability distribution of the number of failure $\mathrm{X}$, before the $\mathrm{K}^{\text {th }}$ success in event that follows a binomial distribution where the probability of success is denoted by $\mathrm{P}$ and failure q i.e (1-P). This distribution is given as.

$\operatorname{Pr}(X=x)=\left(\begin{array}{c}k+x-1 \\ x-1\end{array}\right) p^{k} q^{x} \quad 0 \leq x<\infty$ 
Where

Mean is $k p / p$ and Variance is $k p / p^{2}$

Skewness is $(1+q)(k q)^{\frac{-1}{2}}$ and Kurtosis is $3+\frac{6}{k}+\frac{p 2}{k q}$

\section{Data Presentation and Analysis}

This section focused on the interpretation of result from the analyses carried out on the data collected from World Health Organization (WHO, 2018).

Table 1: Descriptive Statistics.

\begin{tabular}{|c|c|c|c|c|c|}
\hline Variable | & Obs & Mean & Std. Dev. & Min & $\operatorname{Max}$ \\
\hline tbcases & 170 & 45781.76 & 97461.78 & 2300 & 407000 \\
\hline hivcases & 170 & 37634.33 & 87490.38 & 945.1238 & 331400.1 \\
\hline
\end{tabular}

Table 1 above show Over dispersion i.e (Variance > Mean) in both cases of TB and HIV. TB having a mean of 44781.76 with a variance of 9498798561 , while HIV has a mean of 37634.33 with variance of 7640399712 . This clearly showed that there is evidence of over dispersion of the data set. It should be noted that this is happening because it is common with count data to have a problem of over dispersion which implies that the observed variance is higher than the variance of a theoretical model. This problem will affect the Poisson regression negatively and will be corrected by the negative binomial regression model. 


\section{Incident of TB and HIV cases in Benin from 2000-2016}

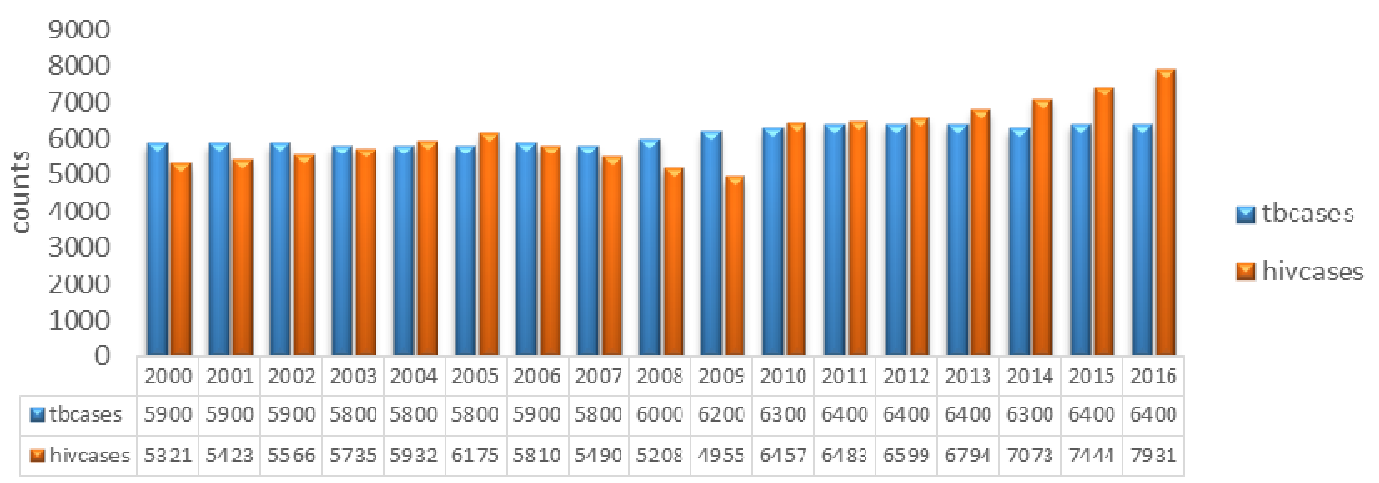

Fig 1: Shows the prevalence rate of TB and HIV in Benin from 2000-2016.

Fig 1 above chat shows the prevalence rate of TB and HIV in Benin from 2000 to 2016, with the highest rate of incidence cases in 2016 with a total of 6400 and 7931 cases recorded for TB and HIV respectively. However between this 16years period TB and HIV were on the increase by $8.50 \%$ and $49.10 \%$ respectively. It should also be noted here that $\mathrm{TB}$ has been on oscillatory trend as it have been oscillating between 5900 to 6400 within this period in the meantime HIV been on a steady increment leading to $49.1 \%$ increment.

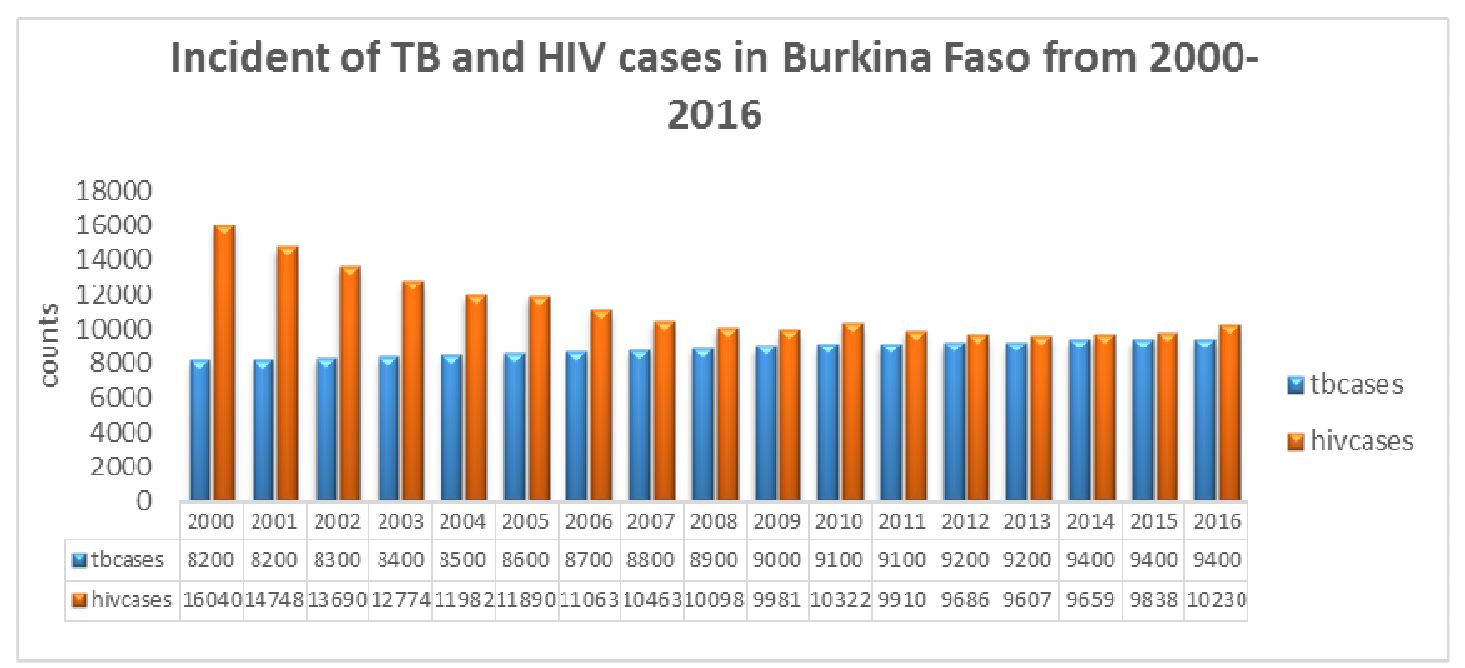

Fig 2: Shows the prevalence rate of TB in Burkina Faso from 2000-2016. 
Fig 2 above chat shows the prevalence rate of TB and HIV in Burkina Faso from 2000 to 2016 with the highest rate of incidence cases of TB in 2016 totaling 9400 cases while HIV recorded its highest count in 2000 with a total of 16040 and $36.22 \%$ decrease with the 16years period however TB has being on the increase with $14.60 \%$ increase from 2000 to 2016 . Leading to a downward trend in HIV while there is an upward trend in TB over this period of time.

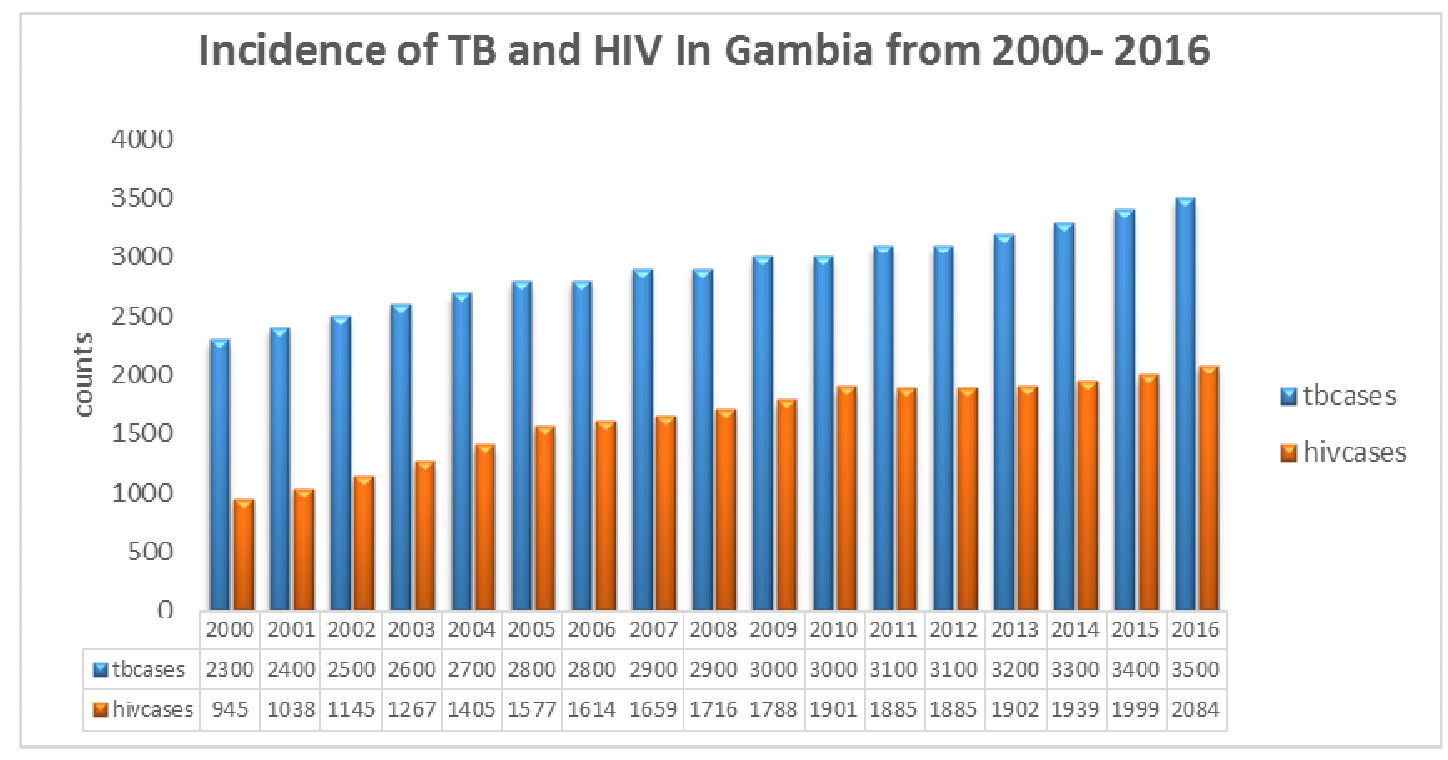

Fig 3:

Shows the prevalence rate of TB and HIV in Gambia from 2000-2016.

Fig 3 above shows the chat of prevalence rate of TB and HIV in Gambia with the highest rate of incidence cases of both TB and HIV recorded in 2016 to be 3500 and 2084 respectively. However from 2000 to 2016 there have being a steady increase of $4.3 \%$ and $120.53 \%$ for TB and HIV respectively. 


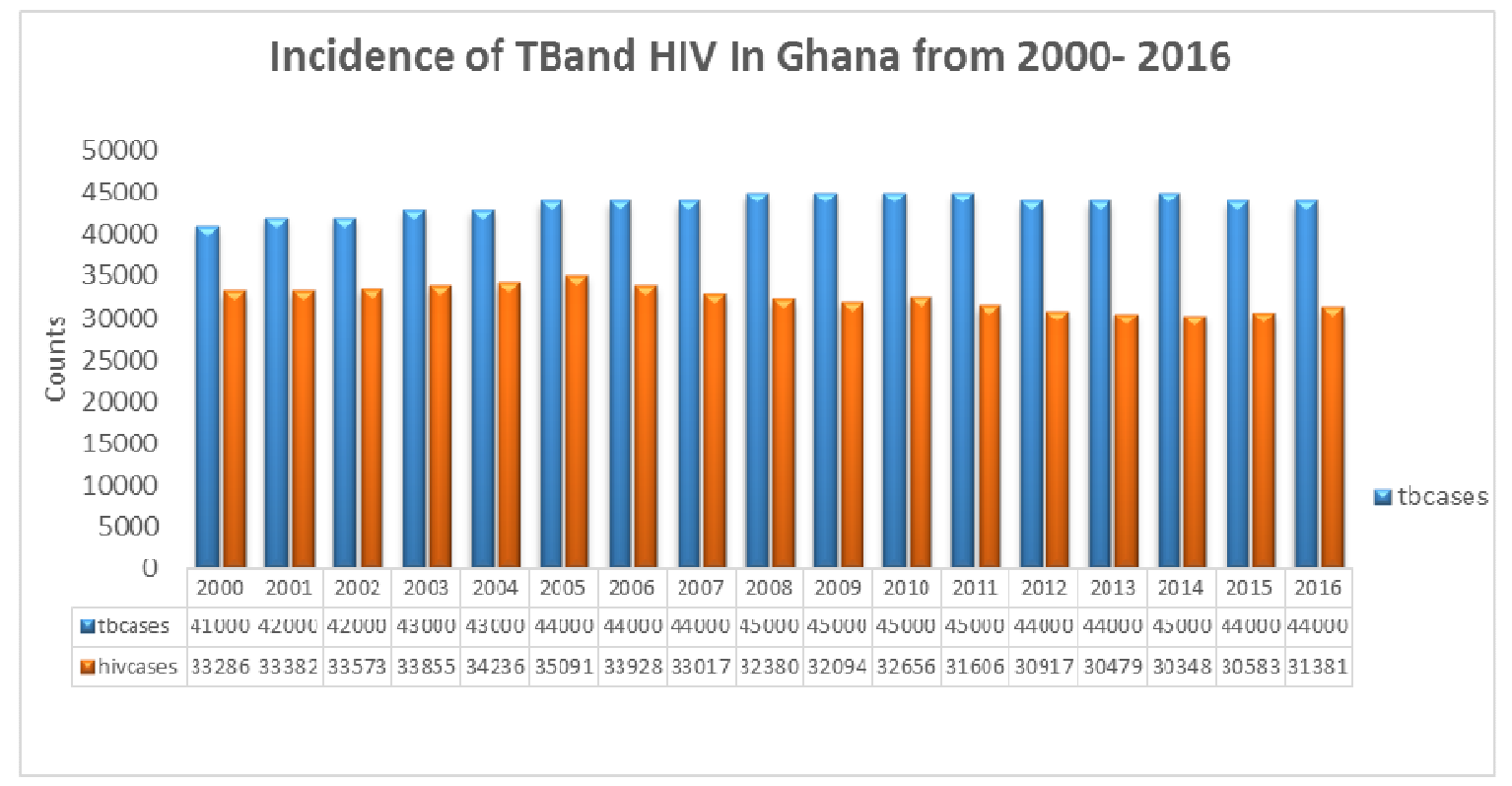

Fig 4: Shows the prevalence rate of TB and HIV in Ghana from 2000-2016.

Fig 4 above shows the chat of prevalence rate of TB and HIV in Ghana with the highest cases of HIV recorded between 2000 and 2005 with an increasing rate of $5.42 \%$ after which there was a decline in case of $12.85 \%$ in HIV between $2005-2015$ but between 2015 and 2016 it rose with about $2.6 \%$ cases. However incidence cases of TB has been on a steady increase of $9.76 \%$ from 2000 to and 2010 and later showed a 2.22\% decrease from 2010-2016.

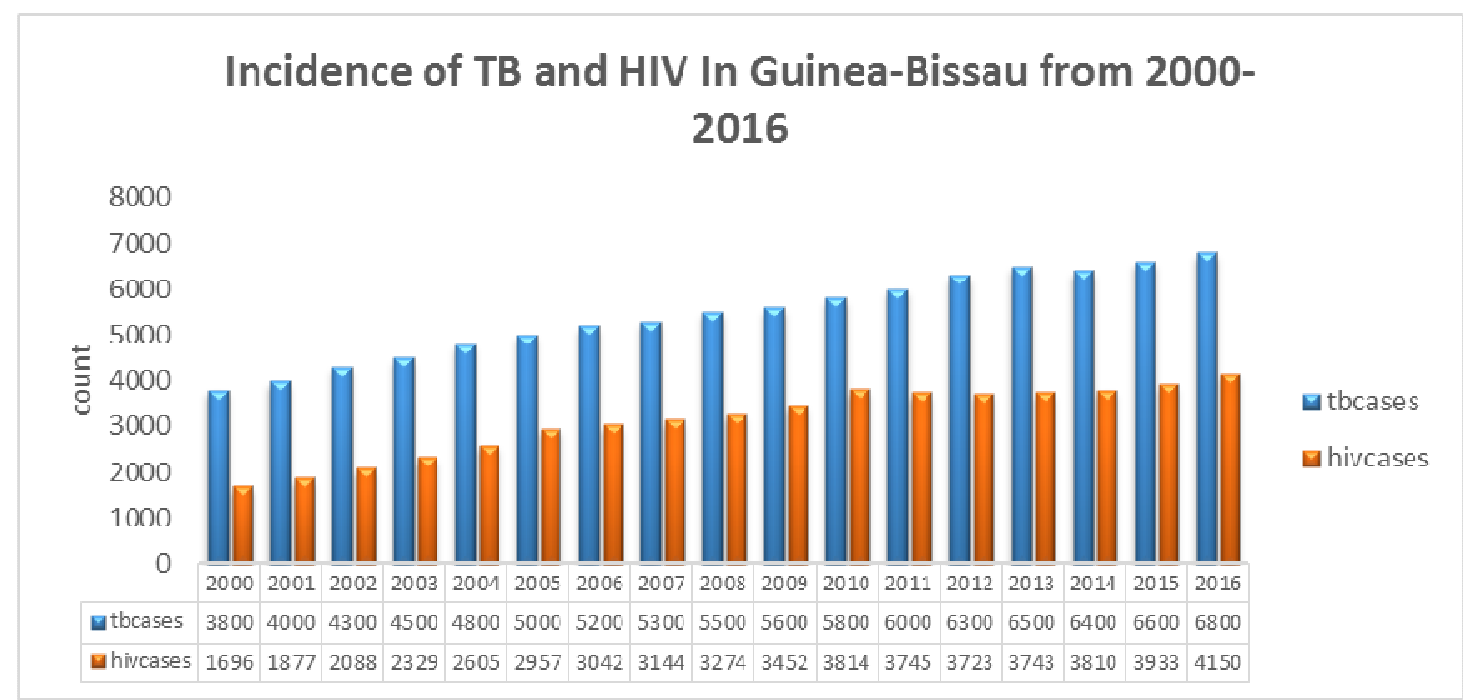

Fig 5: Shows the prevalence rate of TB and HIV in Guinea-Bissau from 2000-2016. 
Fig 5 above chat shows the prevalence rate of TB and HIV in Guinea-Bussau with the highest rate of incidence cases recorded in 2016 to be 6800 cases. There was a steady increase rate of 78.95\% in TB incident cases between 2000 and 2016 it reveals and upward trend of the infection. Similarly HIV followed the same trend of upward movement with the highest rate of incidence cases recorded in 2016 to be 4150 cases. There was a steady increase rate of $144.69 \%$ in HIV incident cases between 2000 and 2016.

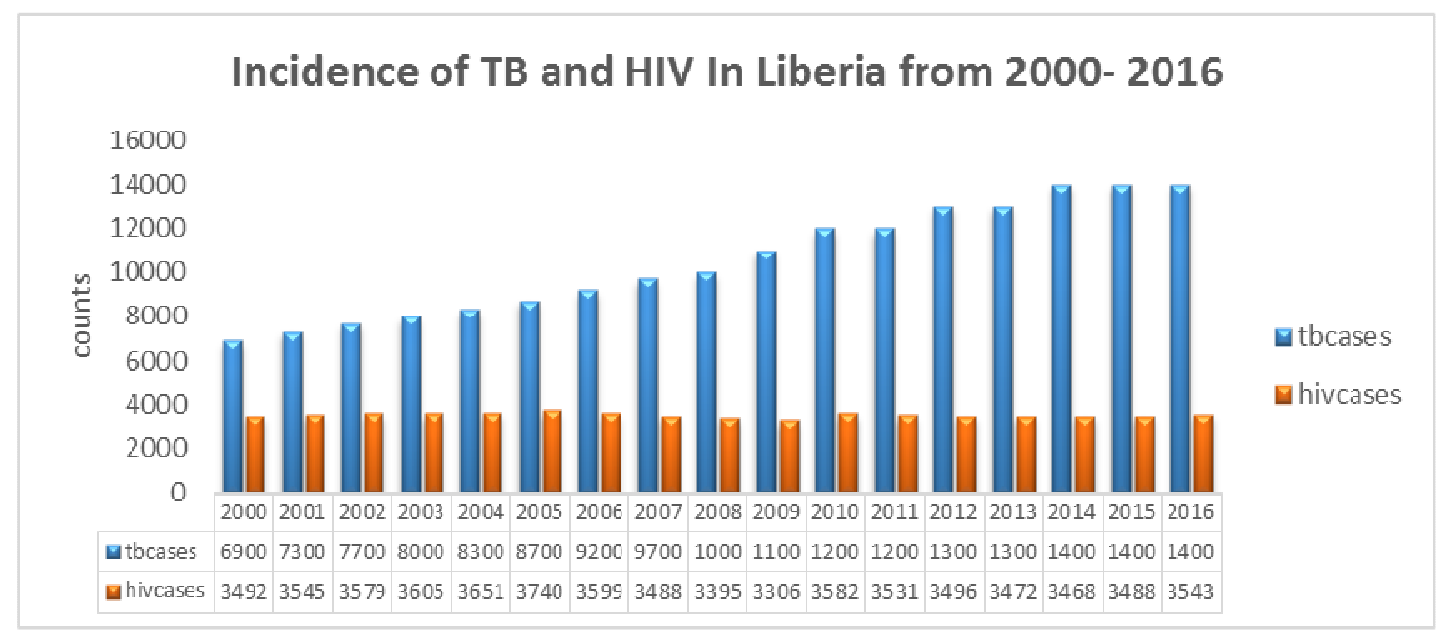

Fig 6: Shows the prevalence rate of TB and HIV in Liberia from 2000-2016.

Fig 6 above chat shows the prevalence rate of TB and HIV in Liberia with the highest rate of incidence cases recorded in 2014-2016 to be 14000 cases in each year. There was a steady increase rate of $108.90 \%$ in TB incident cases between 2000 and 2016 it reveals and upward trend of the infection. In the cases of HIV there was an upward trend between 2000-2005, with a 7.10\% increase rate but later between 2005-2016 there downward rate of 5.27\% in HIV incident cases. 


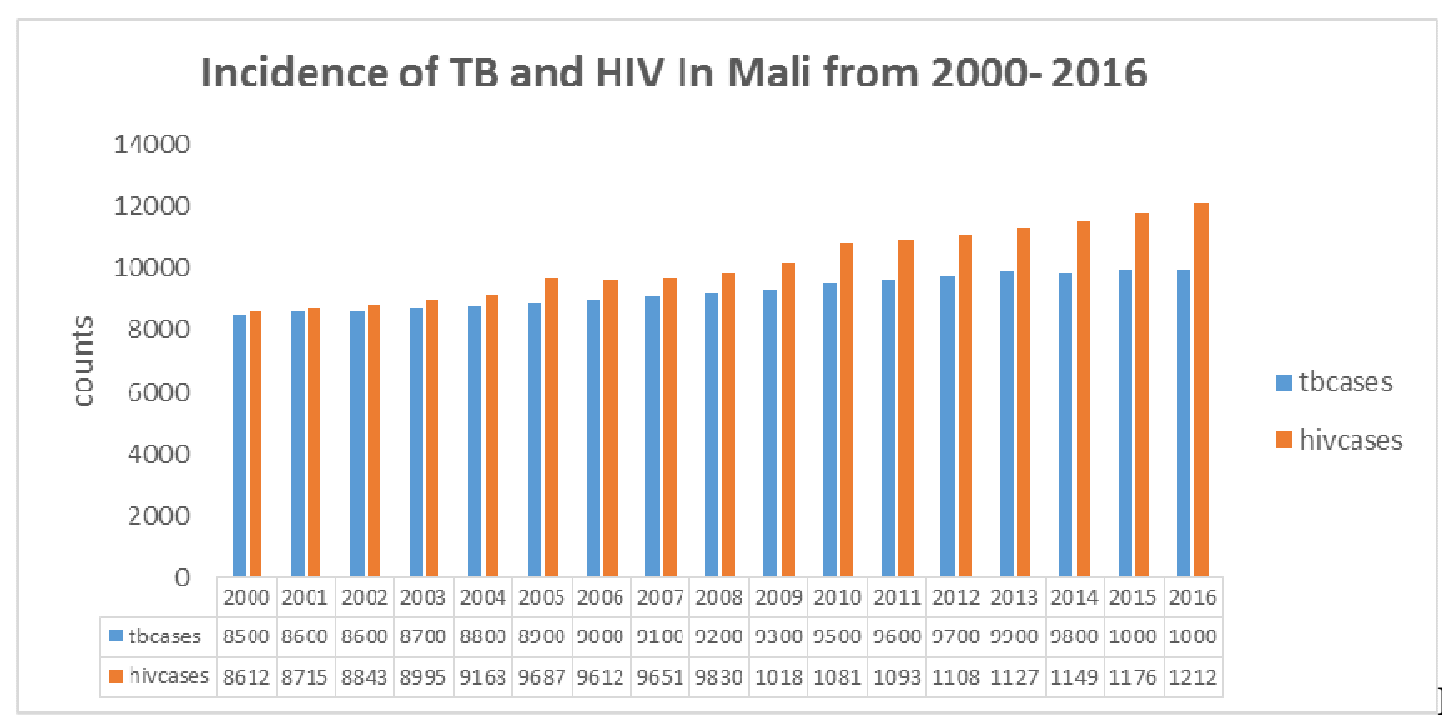

Shows the prevalence rate of TB and HIV in Mali from 2000-2016.

Fig 7 above chat shows the prevalence rate of TB and HIV in Mali with the highest rate of incidence cases recorded in 2016 to be 10000 cases. There was a steady increase rate of $17.65 \%$ in TB incident cases between 2000 and 2016 it reveals and upward trend of the infection. Similarly HIV followed the same trend of upward movement with the highest rate of incidence cases recorded in 2016 to be 12120 cases. There was a steady increase rate of $40.73 \%$ in HIV incident cases between 2000 and 2016.

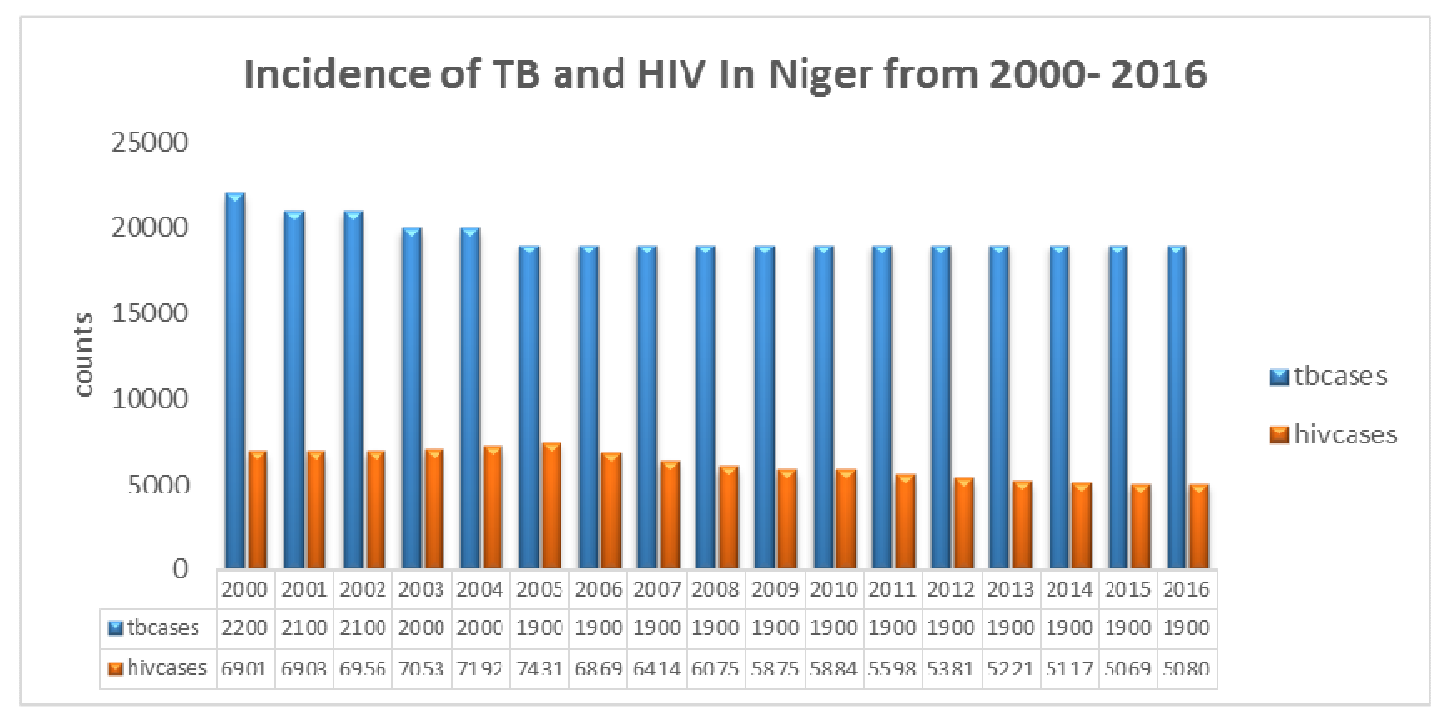




\section{Fig 8: Shows the prevalence rate of TB and HIV in Niger from 2000-2016.}

Fig 8 above shows the prevalence rate of TB in Niger with the highest rate of incidence cases recorded in 2000 to be 22000 cases after which it maintained a steady 19000 from 2004-2016 with a 13.63\% decrease in TB incident cases between 2000 and 2016. Similarly HIV has been on the decrease of $22.35 \%$ between 2000 and 2016 .

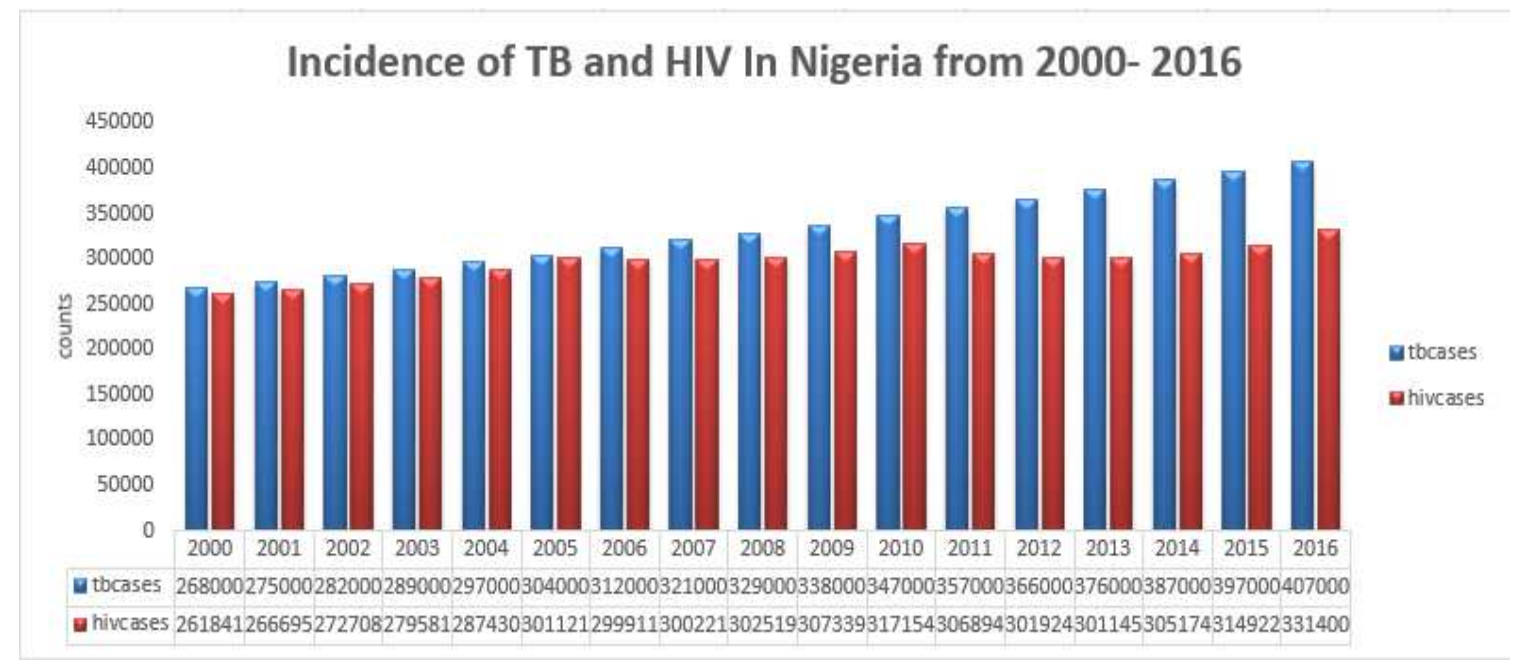

Fig 9: Shows the prevalence rate of TB and HIV in Nigeria from 2000-2016.

Fig 9 above chat shows the prevalence rate of TB and HIV in Nigeria from 2000 to 2016, with the highest rate of incidence cases in 2016 with a total of 407000 and 331400 cases recorded for TB and HIV respectively. However between this 16years period TB and HIV were on the increase by $51.87 \%$ and $26.57 \%$ respectively. 


\section{Incidence of TB and HIV In Sierra leone from 2000- 2016}

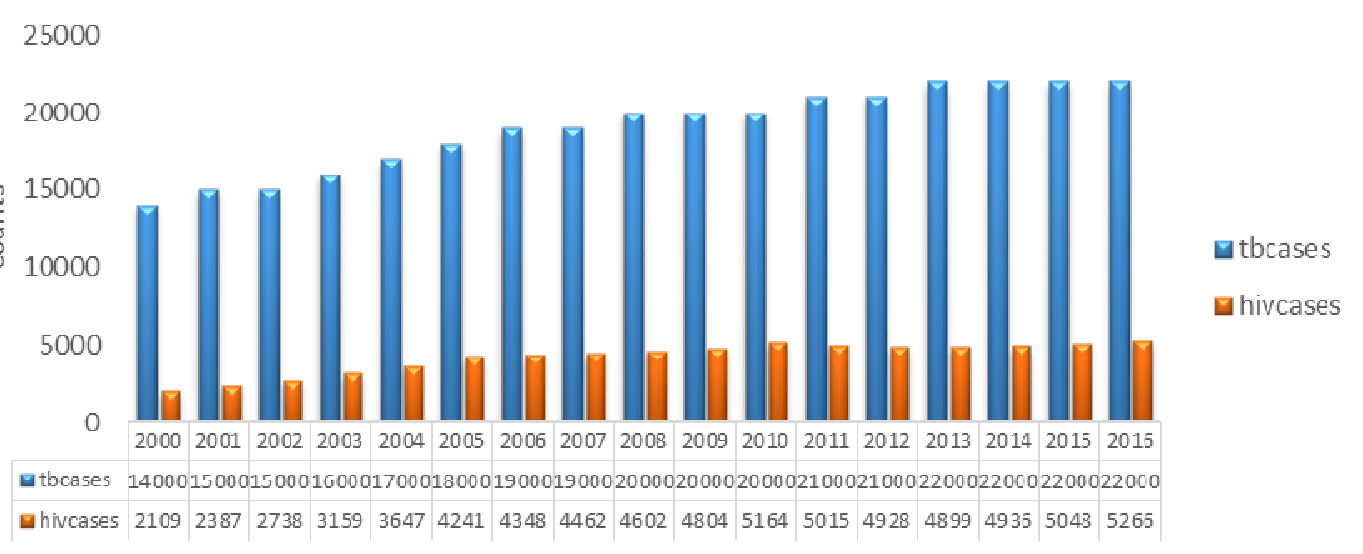

\section{Fig 10: Shows the prevalence rate of TB and HIV in Sierra Leone .}

Fig 10 above chat shows the prevalence rate of TB in Sierria leone from 2000 to 2016, with the highest rate of incidence cases in 2013-2016 with a uniform total of 2200 cases recorded. However between this 16years period TB and HIV were on the increase by $57.14 \%$ and $149.69 \%$ respectively.

\section{Table 2: Panel Poisson regression model with random effect}

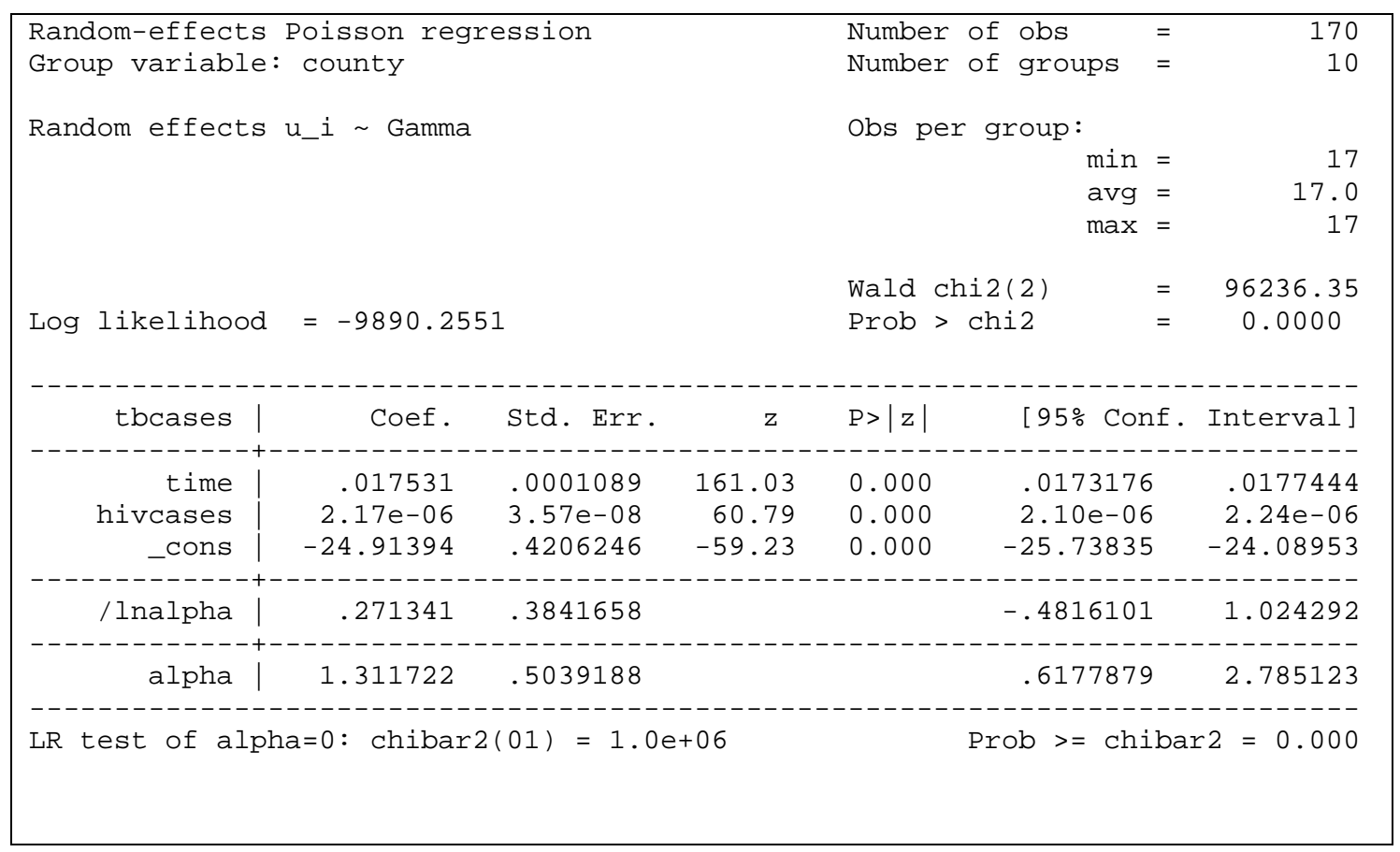


Table 2 above random effect shows that there is a positive trend in TB cases in West African countries $($ Time $=0.01753, \mathrm{P}$-value $=0.000)$ this implies that overtime as there is an increase in the cases of TB and HIV. In addition HIV cases in West Africa react positively to TB cases in West Africa (HIV cases $=2.17 \mathrm{e}-06$, P-value $=0.000)$ which also implies that as the number of HIV cases increases so also the number of people living with TB increases. Having a negative constant value (const $=-24.91394, \mathrm{P}$-value $=0.000)$ simply shows that while there is no effect of HIV case to TB case the expected number of cases tends towards negative meaning as the number of HIV cases reduces the number of TB cases also will reduce or might likely tends toward zero

Table 3: Panel Poisson regression model with conditional fixed effects

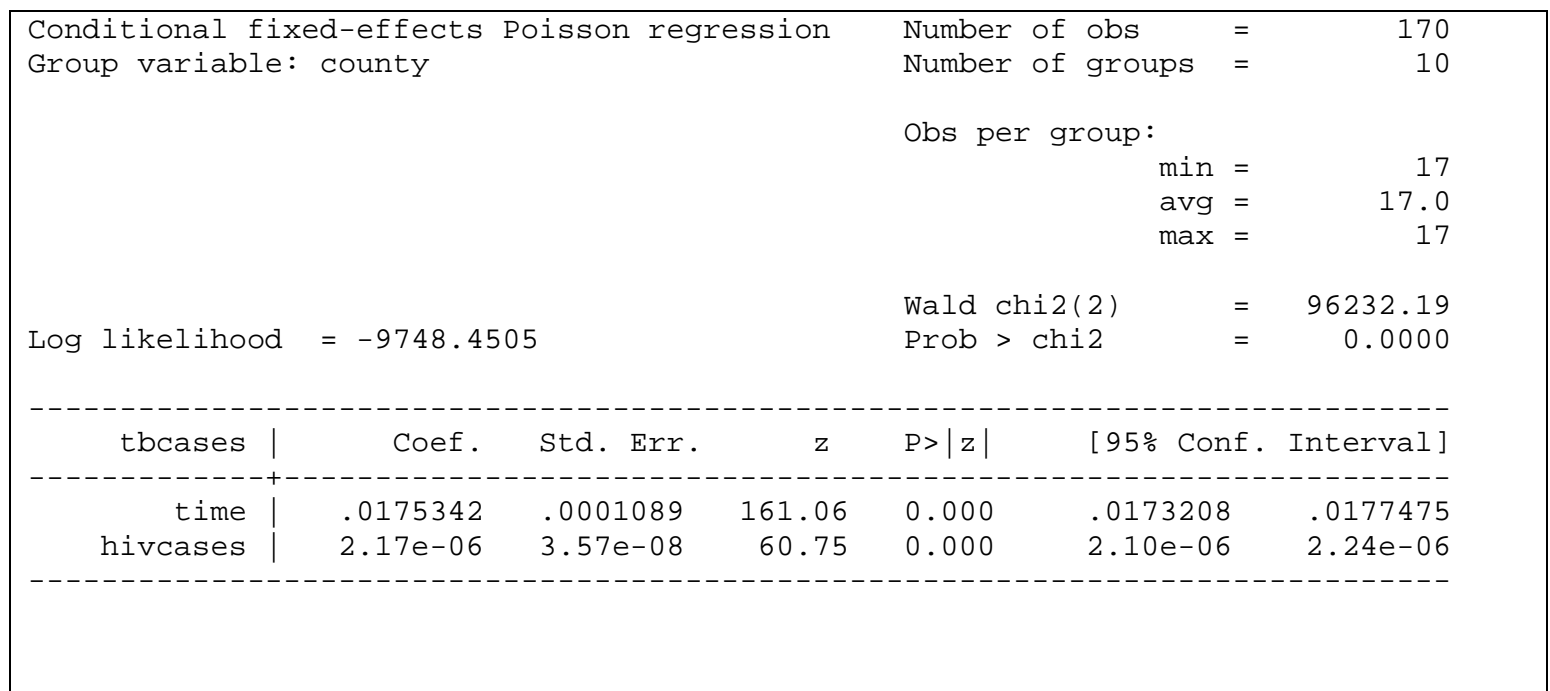

Table 3, above showing Poisson regression model with conditional fixed effects also show that there is a positive trend in TB cases in West African countries $($ Time $=0.01753$, P-value $=$ 0.000) this implies that overtime as there is an increase in the cases of TB and HIV. In addition HIV cases in West Africa react positively to TB cases in West Africa (HIV cases $=2.17 \mathrm{e}-06$, P- 
value $=0.000)$ which also implies that as the number of HIV cases increases so also the number of people living with TB increases.

Table 4: Negative binomial panel regression with random effects.

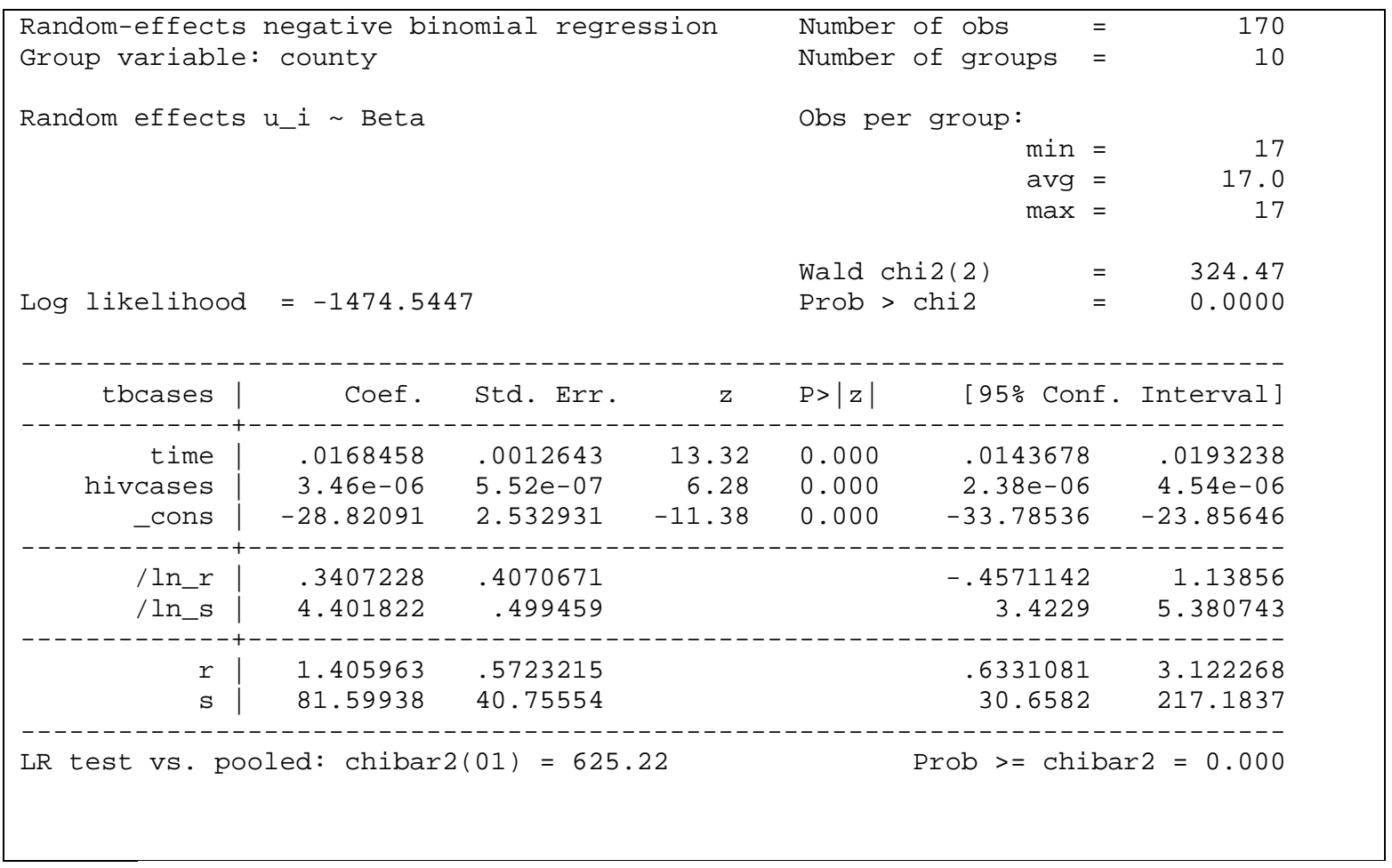

The above table 4: Negative binomial panel regression with random effects showed that there is a positive trend in TB cases in West African countries $($ Time $=.0168458, \mathrm{P}$-value $=0.000)$ this implies that overtime as there is an increase in the cases of TB and HIV. In addition HIV cases in West Africa react positively to TB cases in West Africa (HIV cases $=3.46-06$, P-value $=0.000$ ) which also implies that as the number of HIV cases increases so also the number of people living with TB increases. Having a negative constant value (const $=-28.82091, \mathrm{P}$-value $=0.000$ ) simply shows that while there is no effect of HIV case to TB case the expected number of cases tends towards negative meaning as the number of HIV cases reduces the number of TB cases also will reduce or might likely tends toward zero. 
Table 5: Negative binomial panel regression with Fixed effects.

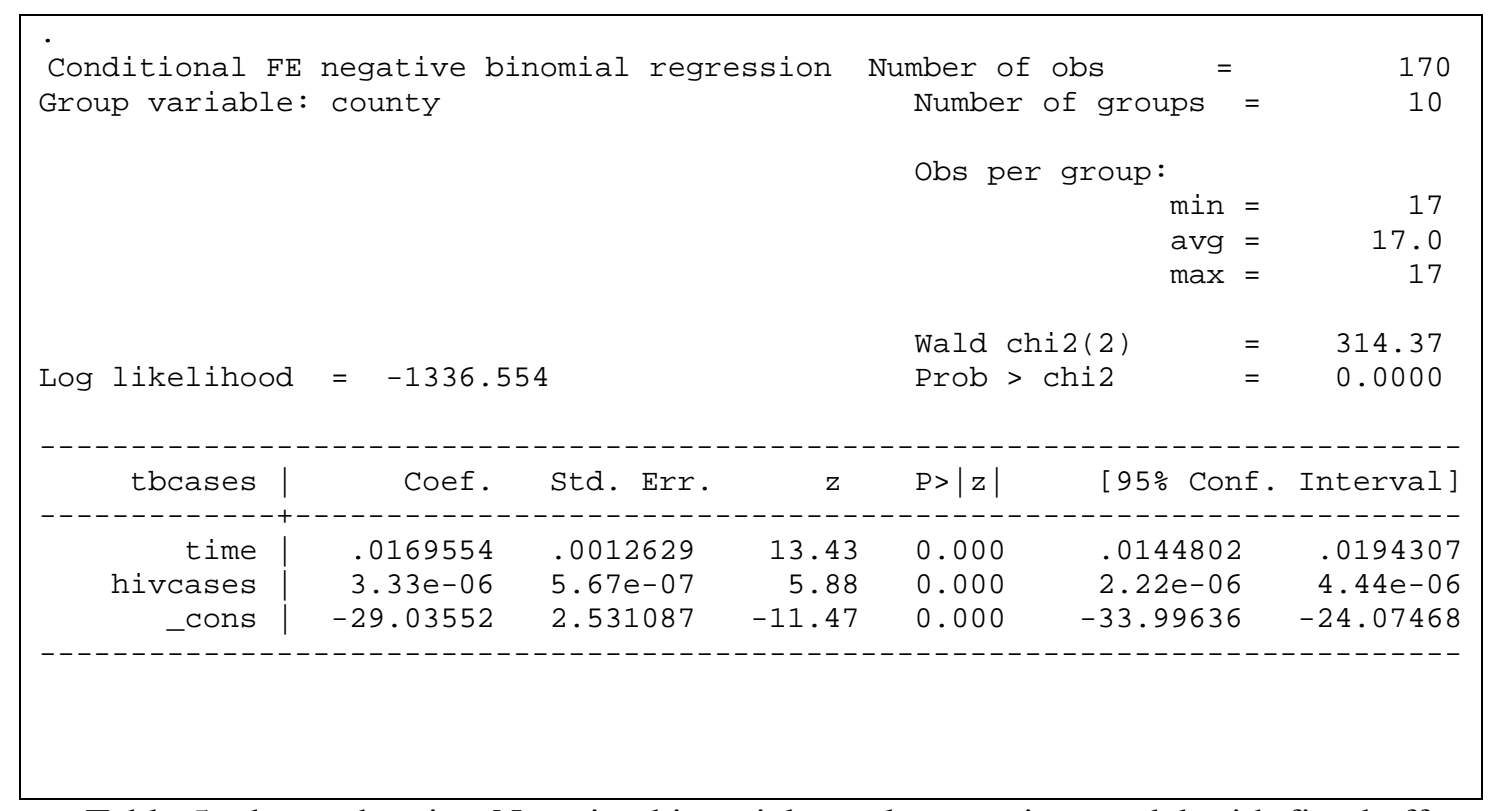

Table 5, above showing Negative binomial panel regression model with fixed effects also show that there is a positive trend in TB cases in West African countries $($ Time $=.0169554$, P-value $=$ 0.000) this implies that overtime as there is increase in the cases of TB and HIV. In addition HIV cases in West Africa react positively to TB cases in West Africa (HIV cases $=3.33 \mathrm{e}-06, \mathrm{P}$-value $=0.000)$ which also implies that as the number of HIV cases increases so also the number of people living with TB increases. Having a negative constant value $($ const $=-29.03552, \mathrm{P}-\mathrm{value}=$ 0.000) simply shows that while there is no effect of HIV case to TB case the expected number of cases tends towards negative meaning as the number of HIV cases reduces the number of TB cases also will reduce or might likely tends toward zero

Table 6: Log likelihood statistic for the Panel Models.

\begin{tabular}{|c|c|}
\hline Panel Model & Log Likelihood \\
\hline Poisson(Random Effect) & -9890.2551 \\
\hline Poisson(Fixed Effect) & -9748.4505 \\
\hline Negative Binomial (Random Effect) & -1474.5447 \\
\hline
\end{tabular}


Negative Binomial(Fixed Effect)

$-1336.554$

Table 6 above which is the log likelihood for Panel data with a Negative Binomial (fixed Effect) of -1336.554 which is higher than the Negative Binomial (Random Effect) of -1474.5447 . Following that the Negative Binomial (fixed Effect) is higher we therefore conclude that Panel Poisson regression model with fixed effect gave a better estimate.

\section{Discussion of Findings}

Over dispersion i.e (Variance > Mean) was found in both cases of TB and HIV. TB having a mean of 44781.76 with a variance of 9498798561 , while HIV has a mean of 37634.33 with variance of 7640399712. This clearly showed that there is evidence of over dispersion of the data set. It should be noted that this is happening because it is common with count data to have a problem of over dispersion which implies that the observed variance is higher than the variance of a theoretical model. This is common with count data (Famoye et al., 2004). This problem will affect the Poisson regression negatively and will be corrected by the negative binomial regression model. The prevalence rate of TB and HIV in Benin from 2000 to 2016, with the highest rate of incidence cases in 2016 with a total of 6400 and 7931 cases recorded for TB and HIV respectively. However between this 17years period TB and HIV were on the increase by $8.50 \%$ and $49.10 \%$ respectively. It should also be noted here that TB has been on oscillatory trend as it have been oscillating between 5900 to 6400 within this period in the meantime HIV been on a steady increment leading to $49.1 \%$ increment. The prevalence rate of TB and HIV in Burkina Faso from 2000 to 2016 with the highest rate of incidence cases of TB in 2016 totaling 9400 cases while HIV recorded its highest count in 2000 with a total of 16040 and $36.22 \%$ decrease with the $16 y$ ears period however TB has being on the increase with $14.60 \%$ increase 
from 2000 to 2016. Leading to a downward trend in HIV while there is an upward trend in TB over this period of time. The prevalence rate of TB and HIV in Gambia with the highest rate of incidence cases of both TB and HIV recorded in 2016 to be 3500 and 2084 respectively. However from 2000 to 2016 there have being a steady increase of $4.3 \%$ and $120.53 \%$ for TB and HIV respectively. The prevalence rate of TB and HIV in Ghana with the highest cases of HIV recorded between 2000 and 2005 with an increasing rate of $5.42 \%$ after which there was a decline in case of $12.85 \%$ in HIV between 2005-2015 but between 2015 and 2016 it rose with about $2.6 \%$ cases. However incidence cases of TB has been on a steady increase of $9.76 \%$ from 2000 to and 2010 and later showed a 2.22\% decrease from 2010-2016. The prevalence rate of TB and HIV in Guinea-Bussau with the highest rate of incidence cases recorded in 2016 to be 6800 cases. There was a steady increase rate of $78.95 \%$ in TB incident cases between 2000 and 2016 it reveals and upward trend of the infection. Similarly HIV followed the same trend of upward movement with the highest rate of incidence cases recorded in 2016 to be 4150 cases. There was a steady increase rate of $144.69 \%$ in HIV incident cases between 2000 and 2016. The prevalence rate of TB and HIV in Liberia with the highest rate of incidence cases recorded in 2014-2016 to be 14000 cases in each year. There was a steady increase rate of $108.90 \%$ in TB incident cases between 2000 and 2016 it reveals and upward trend of the infection. In the cases of HIV there was an upward trend between 2000-2005, with a 7.10\% increase rate but later between 20052016 there downward rate of $5.27 \%$ in HIV incident cases. The prevalence rate of TB and HIV in Mali with the highest rate of incidence cases recorded in 2016 to be 10000 cases. There was a steady increase rate of $17.65 \%$ in TB incident cases between 2000 and 2016 it reveals and upward trend of the infection. Similarly HIV followed the same trend of upward movement with the highest rate of incidence cases recorded in 2016 to be 12120 cases. There was a steady 
increase rate of $40.73 \%$ in HIV incident cases between 2000 and 2016. TB in Niger has the highest rate of incidence cases recorded in 2000 to be 22000 cases after which it maintained a steady 19000 from 2004-2016 with a 13.63\% decrease in TB incident cases between 2000 and 2016. Similarly HIV has been on the decrease of $22.35 \%$ between 2000 and 2016. The prevalence rate of TB and HIV in Nigeria from 2000 to 2016, with the highest rate of incidence cases in 2016 with a total of 407000 and 331400 cases recorded for TB and HIV respectively. However between this $16 y e a r s$ period TB and HIV were on the increase by $51.87 \%$ and $26.57 \%$ respectively. The prevalence rate of TB in Sierria leone from 2000 to 2016, with the highest rate of incidence cases in 2013-2016 with a uniform total of 2200 cases recorded. However between this 16years period TB and HIV were on the increase by $57.14 \%$ and $149.69 \%$ respectively.

Table 2 above random effect shows that there is a positive trend in TB cases in West African countries $($ Time $=0.01753, \mathrm{P}$-value $=0.000)$ this implies that overtime as there is an increase in the cases of TB and HIV. In addition HIV cases in West Africa react positively to TB cases in West Africa (HIV cases $=2.17 \mathrm{e}-06, \mathrm{P}$-value $=0.000)$ which also implies that as the number of HIV cases increases so also the number of people living with TB increases. Having a negative constant value (const $=-24.91394, \mathrm{P}$-value $=0.000)$ simply shows that while there is no effect of HIV case to TB case the expected number of cases tends towards negative. This result is similar to the findings of Askar (2008).

The analysis carried out using Poisson regression model with conditional fixed effects also show that there is a positive trend in TB cases in West African countries $($ Time $=0.01753$, P-value $=$ 0.000) this implies that overtime as there is an increase in the cases of TB and HIV. In addition HIV cases in West Africa react positively to TB cases in West Africa (HIV cases $=2.17 \mathrm{e}-06$, P- 
value $=0.000)$ which also implies that as the number of HIV cases increases so also the number of people living with TB increases (Njepuome and Odume, 2009).

The Negative binomial panel regression with random effects showed that there is a positive trend in TB cases in West African countries (Time $=.0168458$, P-value $=0.000$ ) this implies that overtime as there is an increase in the cases of TB and HIV. In addition HIV cases in West Africa react positively to TB cases in West Africa (HIV cases $=3.46-06$, P-value $=0.000$ ) which also implies that as the number of HIV cases increases so also the number of people living with TB increases. Having a negative constant value (const $=-28.82091$, P-value $=0.000$ ) simply shows that while there is no effect of HIV case to TB case the expected number of cases tends towards negative (Cajetan, et al., 2017).

Also Negative binomial panel regression model with fixed effects from the analysis also show that there is a positive trend in TB cases in West African countries $($ Time $=.0169554$, P-value $=$ 0.000) this implies that overtime as there is increase in the cases of TB and HIV. In addition HIV cases in West Africa react positively to TB cases in West Africa (HIV cases $=3.33 \mathrm{e}-06, \mathrm{P}$-value $=0.000)$ which also implies that as the number of HIV cases increases so also the number of people living with TB increases. Having a negative constant value $($ const $=-29.03552, \mathrm{P}$-value $=$ 0.000) simply shows that while there is no effect of HIV case to TB case the expected number of cases tends towards negative (Cajetan et al., 2017).

In the overall, the Panel Negative Binomial regression Model (fixed) emerged as the superior model for modeling TB and HIV cases in West African counties using the log likelihood statistic as a means for model selection. 


\section{Conclusion and Recommendations}

This study concludes that trend of tuberculosis case in West Africa is increasing over time while the increase in HIV cases leads to increase in Tuberculosis cases in West Africa. Lastly Panel Negative Binomial Regression Model (Fixed effect) was superior in modeling TB and HIV cases in West African countries. Based on the findings of this dissertation the following recommendations are made

i. More efforts should be channeled toward Awareness campaign and education of patient on the mode of transmission of TB and HIV across West Africa countries and community particularly the rural areas.

ii. The medical sectors in West African countries should come up with a systematic program aimed at maintaining and combating against the present situation of $\mathrm{TB}$ and HIV in each of their respective countries.

iii. There should be a referral mechanism for patients suspected of having TB disease to be investigated in the TB diagnostic centre and started on treatment, if indicated

iv. International organization and NGO's should engage more in programmes geared to TB/HIV collaboration

v. Environmental control programs should be put in place in most West African communities by the government which will include the supply of Ultraviolet germicidal irradiation.

vi. Individual should keep a more ventilated homes. 


\section{References}

Akinleye, O. M., Alo, O. G., Salami, O. O., Alaka - Coker, A. A., Idris M. G. and Onyeoghani N. (2015): Tuberculosis and HIV co-infection among patients attending directly observed treatment short course (DOTS) in Lagos, Nigeria. Archives of Applied Science Research, 2015, 7 (7):69-74

Andrzej, P., Marianne, J., Markus, S., Martins, E. R. and Gunilla, K. (2012): Tuberculosis and HIV co-infection. US National Library of Medicine National Institute of Health.

Askar, A. H. O. (2008): Tuberculosis and HIV Coinfection in two Districts in Sumaliland Academic Dissertation, University of Tampere.

Aweke, A. M., Zelalem, G. D., Essey, K. M. and Demeke, L. W. (2016): Prevalence and associated factors of TB/HIV co-infection among HIV Infected patients in Amhara region, Ethiopia, US National Library of Medicine National Institutes of Health16(2): $588-595$.

Baltagi, B. (2011): Econometric analysis of panel data. New York, NY: Wiley.

Brosch, R., Gordon, S. V., Marmiesse, M., et al., (2002): "A new evolutionary scenario for the Mycobacterium tuberculosis complex," Proceedings of the National Academy of Sciences of the United States of America, 99(6):3684-3689

Cajetan, C., Oyedumi, Issac, A., and Akwaja, K. (2017): Prevalence of Drug-Resistant Tuberculosis in Nigeria. A Systematic Review and Meta-analysis.

Cegielski, J. P., and McMurray, D. N. (2004): "The relationship between malnutrition and tuberculosis: evidence from studies in humans and experimental animals," International Journal of Tuberculosis and Lung Disease, 8(3):286-298.

Chatterjee, D., Pramanik, A. K. (2015): Tuberculosis in the African continent: A comprehensive review: Pathophysiology. 2015 Mar;22(1):73-83. doi: 10.1016/j.pathophys.2014.12.005. Epub 2015 Jan 14.

De Cock, K. M., Soro, B., Coulibaly, I. M. and Lucas, S. B. (1992): "Tuberculosis and HIV infection in sub-Saharan Africa," Journal of the American Medical Association, 268(12):1581-1587

Evans, D. B., and Etienne, C. (2010): "Health systems financing and the path to universal coverage," Bulletin of the World Health Organization, 88(6):402

Gehre, F., Kumar, S., Kendall, L., et al (2016): A Mycobacterial Perspective on Tuberculosis in West Africa: Significant Geographical Variation of M. africanum and other M. tuberculosis Complex Lineages: Published: March 10, 2016 https://doi.org/10.1371/journal.pntd.0004408 
Greene, W. (1997). Econometric analysis. Upper Saddle River, NJ: Prentice Hall.

Houben, R. M., and Dodd, P. J (2016): The Global Burden of Latent Tuberculosis Infection: A Re-estimation Using Mathematical Modelling. PLoS Med. 2016 Oct 25;13(10):e1002152. doi: 10.1371/journal.pmed.1002152. eCollection 2016 Oct.

Kennedy, P. (2008). A guide to econometrics. Malden, MA: Blackwell.

Laura, B. N., Kieran, R., Sally H. and Jon S. F. (2018): Multidrug-resistant tuberculosis adherence in migrants: a systematic review and meta-analysis. BMC Medicine201816:27

Matteelli, A., Centis, R., D’Ambrosio, L.and Migliori, G. B. (2012): Multidrug- resistant tuberculosis today: Bull World Health Organ. 2012 Feb 1; 90(2): 78. doi: 10.2471/BLT.11.097360

Migliori, G. B., De Iaco, G., Besozzi, G., Centis, R. and Cirillo, D. M. (2007): "First tuberculosis cases in Italy resistant to all tested drugs," Eurosurveillance, 12,(20):20,Article ID E070517.1.

Musa, B. M., Adamu, A. L., et al. (2017): Trends in prevalence of multi drug resistant tuberculosis in sub-Saharan Africa: A systematic review and meta-analysis: PLoS One. 2017; 12(9): e0185105. Published online 2017 Sep 25. doi: 10.1371/journal.pone.0185105.

Njepuome, N. and Odume, B. (2009): The Impact of HIV Syndromes on the treatment of TB cases in Gombe State, Nigeria. Mera African Journal of Respiratory Medicine, 16-20

Parsons, L. M., Somoskövi, Á., Gutierrez, C., et al.,( 2011): "Laboratory diagnosis of tuberculosis in resource-poor Countries: challenges and opportunities," Clinical Microbiology Reviews, 24(2): 314-350.

Paul, C., Claire. C., et al. (2010): The choice between Fixed and Random effect models: Some considerations for Educational Research.

Pimpin, L., Drumright, L. N., et al (2011): Tuberculosis and HIV Co-infection in European Union and European Economic Area Countries. European Respiratory Journal, 38: 1382-1392.

Pontali, E., Pasticci, M. B., Matteelli, A., Baldelli, F. and Migliori, G. B. (2011): Tuberculosis and HIV co-infection: Do we have a Surveillance System in Europe. European Journal 2011 38: 1258-1260 Do1:10.1183/09036.00413111.

Umeh, E.U., Ishaleku, D. and Iheukwumere, C.C. (2007): HIV/Tuberculosis Co- Infection among Patients Attending a Referral Chest Clinic in Nasarawa State, Nigeria. Journal of Applied Sciences, 7: 933-935. 
Velayati, A. A., Masjedi, M. R., Farnia, P. et al., (2009): "Emergence of new forms of totally drug-resistant tuberculosis bacilli: super extensively drug-resistant tuberculosis or totally drug-resistant strains in Iran," Chest, 136(2):420-425.

Wiktor, S. Z., Sassan-Morokro, M., Grant, A. D., et al., (1999): "Efficacy of trimethoprim -sulphamethoxazole prophylaxis to decrease morbidity and mortality in HIV-1-infected patients with tuberculosis in Abidjan, te d'Ivoire: a randomised controlled trial," The Lancet, 353(9163):1469-1475,.

World Health Organization, (2007): "The world health report 2007: a safer future: global public health security in the 21st century," WHO Document WA 530. 1., WHO, Geneva, Switzerland, 2007

World Health Organization, "The global burden of disease: 2004 update," WHO Document W 74, World Health Organization, Geneva, Switzerland, 2008.

World Health Organization, "Molecular line probe assays for rapid screening of patients at risk of multidrug-resistant tuberculosis (MDR-TB)," World Health Organization, Geneva, Switzerland," 2008.

World Health Organization, "Guidelines for the programmatic management of drugresistant tuberculosis: emergency update 2008," Tech. Rep. WHO/HTM/TB/2008. 402, WHO, Geneva, Switzerland

World Health Organization, "The global burden of disease: 2004 update," WHO Document 74, World Health Organization, Geneva, Switzerland, 2008.

World Health Organization,: "Strategie de cooperation de l'OMS avec les pays, 2009_ 2013.

République de Côte d'ivoire," WHO Document WA 540 HC7, World Health Organization, Brazzaville, Congo, 2009.

World Health Organization, "Global tuberculosis control: report 2009," Tech. Rep. WHO/HTM/TB/2009. 411, WHO, Geneva, Switzerland, 2009.

World Health Organization, "Global tuberculosis control: report 2010," Tech. Rep. WHO/HTM/TB/2010. 7, WHO, Geneva, Switzerland, 2010.

World Health Organization, "Global tuberculosis control: key findings from the December 2009 WHO report,” Weekly Epidemiological Record, 85(9): 69-80, 2010.

World Health Organization, "Global tuberculosis control: report 2011," Tech. Rep. WHO/HTM/TB/2011. 16, WHO, Geneva, Switzerland, 2011.

World Health Organization, "Global tuberculosis Report 2012,” Tech. Rep. WHO/HTM/TB/2012. 6, WHO, Geneva, Switzerland, 2012. 
World Health Organization, "Global Tuberculosis report" 2017. World Health Organization, "Who/regional office for Africa" (2017): https://www.afro.who.int/health -topics/tuberculosis-tb

World Health Organization, Tuberculosis and HIV (2019), https://www.who.int/hiv/topics/tb/about_tb/en/ 